\title{
The Object Concept in Human Infants
}

\author{
Commentary on Fields
}

Fei Xu

University of California, Berkeley, Calif., USA

\section{Key Words}

Infant cognition · Object concept · Object individuation and identification

The study of the object concept has had a long tradition in developmental psychology. In any textbook on contemporary developmental psychology, we are guaranteed at least a few paragraphs, often times several pages, on the object concept. Piaget's famous claim about the infants' lack of object permanence - "out of sight, out of mind" - is a paradigmatic example of how to think about developmental changes and progressions. Many parents in our typical American middle-class households have tried out Piaget's experiment in situ: Take an adorable, drooling 7-month-old baby, show her a toy she loves to play with, then cover it with a piece of cloth right in front of her eyes. What do you observe next? The baby does not know what to do to get the toy! She looks around, oblivious to the object's continuing existence under the cloth cover, and turns her attention to something else interesting in her environment. A few months later, the same baby will readily reach out and yank away the cloth cover to retrieve the highly desirable toy. This experiment has been done thousands of times and the phenomenon remains one of the most compelling in all of developmental psychology.

According to Piaget [1954] and his followers, human infants are not born with the concept of an object. They do not understand that objects continue to exist when out of sight. For infants up to about 10 months of age, objects can blink out of existence and come into existence with no apparent cause. Over the course of the first two years, infants gradually construct a concept of object through acting on the objects around them. By the end of this period (i.e., the official end of infancy), a more mature concept of object has been acquired, which marks the end of the sensorimotor stage of development. This is one of many claims Piaget had made to illustrate discontinuities in early childhood development. The infant's starting point is vastly different from what we see later in development, and much constructive learning is needed to get to the more mature concept.

\begin{tabular}{ll}
\hline KARGER & ○ 2013 S. Karger AG, Basel \\
E-Mail karger@karger.com & \\
www.karger.com/hde &
\end{tabular}

Fei Xu

Department of Psychology, University of California

3210 Tolman Hall

Berkeley, CA 94720 (USA)

E-Mail fei_xu@berkeley.edu 
Much of Piaget's stage theory of development has been challenged in the last several decades [see, e.g., Gelman \& Baillargeon, 1983], and one of the celebrated examples is, again, the concept of object [e.g., Baillargeon, Spelke, \& Wasserman, 1985; Spelke, Breinlinger, Macomber, \& Jacobson, 1992 among others]. Our conception of the physical world as consisting of enduring physical objects is so fundamental to us that no theory of developmental psychology can afford not to have an account of it. Baillargeon and her research team, in particular, have made significant contributions to the enterprise of understanding the concept of object and physical reasoning in infancy. They have done painstakingly detailed empirical research on the subject matter, and they have also developed a theoretical proposal synthesizing a large body of work from the last few decades.

In a recent attempt, Baillargeon [2008] argues for a principle of persistence as part of the human infant's innate conceptual repertoire - a biological endowment, thanks to millions of years of evolution. She subsumes two earlier principles proposed by Spelke [1994] and Spelke et al. [1992] - solidity and continuity - under one umbrella principle, and she reviews recent empirical evidence to support this claim. Most importantly, Baillargeon suggests that the principle of persistence explains how infants begin to comprehend their physical world and provides the foundation for much development in the domain of physical reasoning during infancy.

Fields [this issue] takes issue with Baillargeon's principle of persistence. In my view, the author raises several very important issues for developmental psychologists, and makes helpful suggestions for how to go about addressing these questions empirically. I will comment on three of these issues in turn.

Fields asks the question about explanatory power concerning the principle of persistence. He argues that stating the principle does not help us understand anything about how infants process object information. As I see it, the principle of persistence simply tries to say that infants already have some expectations about how objects behave prior to any actual experience with objects. Baillargeon's claim is a strong nativist and controversial one [see, e.g., Johnson, 2011; Johnson, Amso, \& Slemmer, 2003, among others for different theoretical perspectives]. Specifically, the principle of persistence states that infants expect "objects to persist, as they are, in time and space." The principle by itself does not tell us how infants take in their visual experiences about surfaces, textures, figure-and-ground, etc. in order to construct a representation of a particular object. It says that once infants have these object representations, they expect them not to change spontaneously. As such, the principle is not intended to be about the algorithms that infants use to figure out what objects are out there in the world, and Fields is correct in saying that much more empirical investigation is needed to understand these algorithms.

Relatedly, Fields points out that, although we have made progress in understanding the neural underpinning of object representations in adults, much of that literature has been ignored in the infant literature. I completely agree that the work on the neural implementation of object representations is crucial for understanding both the format of object representations in infancy and how the young human brain encodes all relevant aspects of an object in its environment. Some of the discussions on object files and visual attention begin to touch on the subject [e.g., Carey \& Xu, 2001], but where and how objects are represented in the brain may shed important light on understanding the nature of these representations. For example, a puzzling finding in developmental psychology suggests that the knowledge we have uncovered in infants 
with visual habituation methodologies may be inaccessible to toddlers who are asked to make explicit predictions in a similar task. Baillargeon et al. [1985] and Spelke et al. [1992] found that in looking-time tasks, 4- and 5-month-old infants understood that a solid object could not pass through another solid object. Other studies, however, have found that 2.5 -year-old children cannot predict verbally or by pointing where a ball will land if a physical barrier is introduced in its path [Berthier, DeBlois, Poirier, Novak, \& Clifton, 2000; Hood, Carey, \& Prasada, 2000]. These disparate findings point to our lack of understanding of the format of the object representations uncovered in infants. Perhaps these representations are implicit and iconic, and they are not in the format of a language of thought that is supposed to be symbolic and abstract [see Carey, 2009, for an explication]. Paying close attention to the neural implementation of these object representations may be one way to answer the question about representational format.

Fields also raises issues about categorization and re-identification. That is, if infants have a concept of a physical object that does not have many features attached to it, does this mean that infants have categorized many object tokens under the type object? Furthermore, how does the infant re-identify a particular object on different occasions when there are no direct spatiotemporal paths to tell them whether it is the same object or not? These are, in my view, very important questions that need to be addressed empirically. With respect to the issue of categorization, the current literature does not offer much strong evidence. Carey and Xu [2001] and Xu [2007] argued for the idea that the object attention system is responsible for constructing object representations in infants, and the mechanism itself embodies the principles of solidity and continuity. In other words, detecting a violation of solidity or continuity may be used as the criterion for starting to construct a new object representation. On this account, object representations are not fully conceptual, and the categorization is done because the attention mechanism is built to pick out whole bodies from the environment and to ignore specific object features. I do not know if this account is consistent with more recent neuroscience evidence; it would be of great interest to developmental psychologists to find out.

With respect to the issue of re-identification, Fields makes the important point that, at the moment, we do not know much about it, and we need to focus our empirical investigation on this question. Most infant studies that address this issue introduce time gaps that are only a few seconds to a few minutes long, but in real life, we often re-identify objects over longer periods. For example, when an infant sees her mother in the morning and then sees her again after being picked up from daycare, does she understand that this is one and the same person? Similarly, if an infant observes her mother drinking a cup of coffee and then much later observes a coffee cup in the trash can, does she make the inference that this is (probably) one and the same cup? If infants do make these inferences approximately correctly, what are the heuristics that allow them to make the best guesses? I have no doubt that these are important empirical issues that await answers.

The empirical work on the object concept and physical reasoning in infancy has given us a large body of findings to think through. Fields takes the initiative to reflect on this body of research from a philosophical perspective. This is a much-needed exercise, and I applaud his effort. The field of developmental psychology can greatly benefit from such reflections. 


\section{References}

Baillargeon, R. (2008). Innate ideas revisited: For a principle of persistence in infants' physical reasoning. Perspectives on Psychological Science, 3, 2-13.

Baillargeon, R., Spelke, E.S., \& Wasserman, S. (1985). Object permanence in five-month-old infants. Cognition, 20, 191-208.

Berthier, N.E., DeBlois, S., Poirier, C.R., Novak, M.A., \& Clifton, R.K. (2000). Where's the ball? Two- and three-year-olds reason about unseen events. Developmental Psychology, 36, 394-401.

Carey, S. (2009). The origin of concepts. New York, NY: Oxford University Press.

Carey, S., \& Xu, F. (2001). Infants' knowledge of objects: Beyond object files and object tracking. Cognition, 80, 179-213.

Gelman, R., \& Baillargeon, R. (1983). A review of some Piagetian concepts. In P.H. Mussen (Series Ed.), J.H. Flavell, \& E.M. Markman (Vol. Eds.), Handbook of child psychology (4th ed.): Vol. 3. Cognitive development (pp. 167-230). New York, NY: Wiley.

Hood, B.M, Carey, S., \& Prasada, S. (2000). Predicting the outcomes of physical events: Two-year-olds fail to reveal knowledge of solidity and support. Child Development, 71, 1540-1554.

Johnson, S.P. (2011). A constructivist view of object perception in infancy. In L.M. Oakes, C.H. Cashon, M. Casasola, \& D.H. Rakison (Eds.), Infant perception and cognition: Recent advances, emerging theories, and future directions (pp. 51-68). New York, NY: Oxford University Press.

Johnson, S.P., Amso, D., \& Slemmer, J.A. (2003). Development of object concepts in infancy: Evidence for early learning in an eye tracking paradigm. Proceedings of the National Academy of Sciences (USA), $100,10568-10573$.

Piaget, J. (1954). The construction of reality in the child. New York, NY: Routledge.

Spelke, E.S. (1994). Initial knowledge: Six suggestions. Cognition, 50, 431-445.

Spelke, E.S., Breinlinger, K., Macomber, J., \& Jacobson, K. (1992). Origins of knowledge. Psychological Review, 99, 605-632.

Xu, F. (2007). Sortal concepts, object individuation, and language. Trends in Cognitive Sciences, 11, 400 406. 